\title{
BLEEDING OF FEMORAL HEAD DURING TOTAL HIP ARTHROPLASTY FOR OSTEOARTHROSIS
}

\author{
Carlos Roberto Schwartsmann ${ }^{1,2}$, Leandro de Freitas Spinelli ${ }^{2}$, Marco Yánez Sotomayor ${ }^{2}$, Anthony Kerbes Yépez $^{2}$, \\ Leonardo Carbonera Boschin², Marcelo Faria Silvva ${ }^{1}$
}

\section{ABSTRACT}

Objective: To evaluate the bleeding of the femoral head on hip osteoarthritis in patients who underwent total hip arthroplasty. Methods: One hundred and three hips affected by primary hip osteoarthritis were evaluated. After surgical dislocation, the femoral head was divided into four quadrants, and micro perforations were made in order to observe and assess the presence of bleeding, as early type (EB), late type (LB) or without bleeding (WB). Results: We observed early bleeding (EB) in the upper quadrant in 16 hips (15.5\%), late bleeding in 14 hips (13.6\%) and no bleeding (WB) in 73 hips (70.9\%). The anterior quadrant showed EB in 24 hips (23.3\%), LB in 7 hips (6.8\%) and WB in 72 hips (69.9\%). The lower quadrant presented EB in 40 hips (38.8\%), LB 14 hips (13.6\%) and WB in 49 hips (47.6\%). The posterior quadrant showed EB in 39 hips (37.9\%), LB 19 hips (18.4\%) and WB in 45 hips (43.7\%). Comparing BMI and gender, we found no association between these parameters ( $p>0.05)$. Conclusions: The inferior and posterior quadrant had the highest bleeding levels, following the path of the medial circumflex artery. Level of Evidence III, Therapeutic Study.

Keywords: Hip/surgery. Femur head. Osteoarthritis.

Citation: Schwartsmann CR, Spinelli LF, Sotomayor MY, Yépez AK, Boschin LC, Silva MF. Bleeding of femoral head during total hip arthroplasty for osteoarthrosis. Acta Ortop Bras. [online]. 2015;23(5):268-70. Available from URL: http://www.scielo.br/aob.

\section{INTRODUCTION}

The pathophysiology responsible for the development of idiopathic osteoarthritis of the hip is not yet well understood. Hip osteoarthritis is a very common condition and affects most of the population. It gradually affects the activities of daily living, working and leisure activities.

Regarding the vascular anatomy of the hip, the literature presents few studies showing vascular dissection of the proximal femur. Additionally, high definition imaging exams and Doppler vascular flow instruments have been used in anatomical description, as well as diagnostic and therapeutic procedures. The femoral head is infused primarily by the medial circumflex femoral artery (MCFA), through its deep branch, which also originates from 2-4 secondary branches. Among them, the upper and lower posterior branches are the most important. ${ }^{1-11}$ Observing the neck and femoral head medial side, the upper posterior branches can be identified among eleven and fourteen hours and the anterior branches between seventeen and nineteen hours. The posterior branches are commonly present and are of variable size, although the upper posterior group is most consistent and represents the main source of epiphyseal vascular perfusion. ${ }^{11}$ The anterior vascular group is small and inconsistent. The piriformis branch of the inferior gluteal artery is part of the main perfusion source in this region. On the other hand, the branches of the lateral circumflex artery, the obturator artery and the teres ligament represent a minimum contribution for the perfusion of the femoral head. ${ }^{2-6,12-15}$

Changes in the femoral head structure can be explained by intra and extraosseous vascular changes in the level of terminal branches of the cervix and epiphysis. In hypertrophic and idiopathic coxarthrosis it has not yet been possible to determine its pathophysiology, but it is likely that the intraosseous vascular flow in the femoral head is fickle and minor compared to the extraosseous contribution of the retinacular network. The latter is responsible for maintaining the nutrition of the trabecular bone. There are reports of morphological changes in the femoral head after injury of these retinacular vessels during the posterior approach. ${ }^{16}$

The aim of this study was to evaluate the bleeding from the femoral head with osteoarthritis during total hip arthroplasty procedure.

\section{MATERIALS AND METHODS}

In this study 103 arthritic hips without secondary pathologies undergoing total hip arthroplasty have been considered. Cases with previous surgery of the ipsilateral hip, avascular necrosis, rheumatoid arthritis or other rheumatic diseases, tumors,

All the authors declare that there is no potential conflict of interest referring to this article.

\footnotetext{
1. Universidade Federal de Ciências da Saúde de Porto Alegre, Porto Alegre, RS, Brazil.

2. Irmandade Santa Casa de Misericórdia de Porto Alegre, Orthopedic and Traumatology Service, Porto Alegre, RS, Brazil.
}

Work developed at Santa Casa de Misericórdia de Porto Alegre, Orthopedic and Traumatology Service, Porto Alegre, RS, Brazil. Correspondence: Rua Leopoldo Bier, 825, cj 403. 90.620-100 - Porto Alegre, RS, Brazil. schwartsmann@gmail.com 
history of hip disease in childhood or adolescence and peripheral vascular disease have been excluded. No patient was using platelet aggregation inhibitors, coumarin derivate or was subjected to heparin prior to surgery. Anesthesia of patients was performed with lumbar spinal block, using heavy bupivacaine $20 \mathrm{mg}$ and $0.1 \mathrm{mg}$ morphine. Patients were placed in contralateral lateral position to perform a posterior-lateral approach. After opening the fascia lata and muscle and repair of tendons of the external rotator muscles of the hip, articular exposure with the opening of the posterior capsule was performed. The posterior hip dislocation with maximum flexion and internal rotation exposes the femoral head for visualization of the four quadrants (anterior, posterior, superior and inferior). (Figure 1) After completion of the exposure of the joint surface, a puncture was performed in the middle of each quadrant with a $3.2 \mathrm{~mm}$ drill with a $10 \mathrm{~mm}$ depth lock. The bleeding was observed and qualified by registering it as early bleeding (EB: immediate to 10 seconds), late bleeding (LB: after 10 seconds) or without bleeding (WB). (Figure 2) This study was approved by the Institutional Ethics Committee and the patients signed a Free and Informed Consent form.

Among the variables analyzed, gender, age, laterality, body mass index (BMI), degree of osteoarthritis and bleeding according to the quadrant of the femoral head were included. Statistical analysis was performed using SPSS 18, with a 95\% confidence interval.

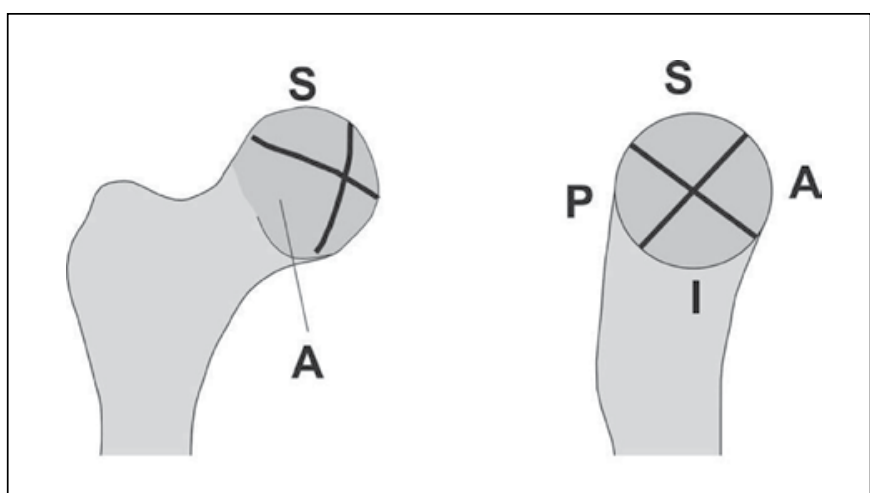

Figure 1. Exposure diagram of the quadrants of the femoral head in surgical hip dislocation. (A) anterior, (P) posterior, (S) superior and (I) inferior quadrants.

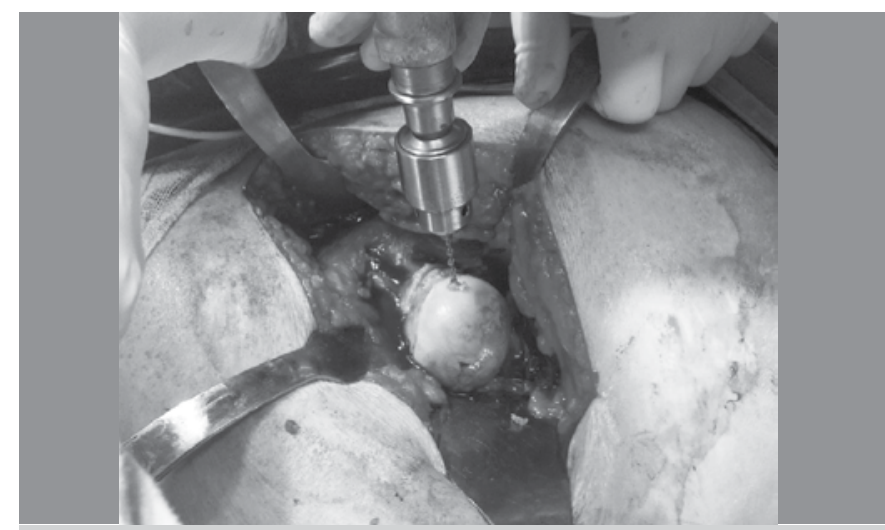

Figure 2. Exposure of the femoral head by the posterior way. Example of $3.2 \mathrm{~mm}$ micro- perforations in the posterior $(P)$ quadrant.

\section{RESULTS}

Forty eight male patients (47\%) and 55 (53\%) female patients, aged $34-89$ years (mean $64 \pm 10$ years old) were analyzed. The mean BMl of patients was $27 \pm 4 \mathrm{~kg} / \mathrm{m}^{2}$, ranging from 20 to 37 . In $45 \%$ of patients, the right side was operated, and in $55 \%$ it was the left side.

It was observed in the upper quadrant early bleeding (EB) in 16 hips (15.5\%), late bleeding in 14 hips (13.6\%) and there was no bleeding (WB) in 73 hips (70.9\%). in the anterior quadrant, EB in 24 hips (23.3\%), LB in seven hips (6.8\%) and WB in 72 hips (69.9\%). In the lower quadrant, EB in 40 hips (38.8\%), LB in 14 hips (13.6\%) and WB in 49 hips (47.6\%). Finally, in the posterior quadrant, EB in 39 hips (37.9\%), LB in 19 hips (18.4\%) and WB in 45 hips (43.7\%). When considered and compared BMl and gender, no association was found ( $p>0.05$ ). (Table 1)

Table 1. General incidence of bleeding in the different regions of the femoral head.

\begin{tabular}{c|c|c|c|c}
\hline Bleeding & Superior (S) & Inferior (I) & Anterior (A) & Posterior (P) \\
\hline Early Bleeding (EB) & $16(15.5 \%)$ & $40(38.8 \%)$ & $24(23.3 \%)$ & $39(37.9 \%)$ \\
\hline Late Bleeding (LB) & $14(13.6 \%)$ & $14(13.6 \%)$ & $7(6.8 \%)$ & $19(18.4 \%)$ \\
\hline No Bleeding (WB) & $73(70.9 \%)$ & $49(47.6 \%)$ & $72(69.9 \%)$ & $45(43.7 \%)$ \\
\hline
\end{tabular}

\section{DISCUSSION}

This study evaluated qualitatively bleeding from the femoral head in hip osteoarthritis regarding the four quadrants defined by the authors. Osteoarthritis is a disease that often deforms significantly the femoral head. Thus, it was expected that the disease caused a modification (interruption or decrease) in blood flow pattern around the neck and femoral head, particularly to the region with the lowest degree of osteoarthritis. The absence of bleeding in the anterior and superior quadrants $( \pm 70 \%)$ could be related to a high incidence of osteoarthritis and/or bone remodeling in this region, responsible for pain and movement limitation.

The intraosseous vascular anatomy of the proximal femur has been described in other studies. ${ }^{1-6,8,11,13,16}$ The main blood supply of the femoral head is through the deep branch of the medial circumflex artery, which is constant in its extra capsular segment originating two to four superior retinacular vessels, and occasionally inferior retinacular vessels. ${ }^{17}$ However, the femoral head could be completely infused exclusively by its superiors retinacular vessels. ${ }^{6}$

On the other hand, among other minor sources, there are the medial epiphyseal artery, responsible for the parafoveal region, the metaphyseal artery branches and lateral femoral circumflex artery. Despite descriptions in the literature, the study of anatomical dissection of the medial circumflex artery by Gautier et al. ${ }^{11}$ and Ganz et al., ${ }^{17}$ the authors found no anastomoses with the ascending branch of the lateral femoral circumflex artery in the femoral neck region. These anastomoses were present only in patients under one year old. Thus, it is confirmed the little representation of the lateral femoral circumflex artery in the vascular supply of the femoral head. On the other hand, that study established a relative frequency of anastomosis between the medial femoral circumflex artery and a branch of the inferior gluteal artery along the piriformis muscle, responsible 
for vascular compensation for any possible injury to the medial femoral circumflex artery.

Despite the different degrees of macroscopic arthritis observed in different patients in the trans- operatory, this factor was not statistically significant in the qualitative assessment of bleeding from the femoral head per quadrants. Regardless of the degree of osteoarthritis, the vasculature to the femoral head seems to follow the path of the main artery. ${ }^{18,19}$

The authors agree that this study has some limitations, mainly due to the fact of presenting bleeding subjectively rather than quantitatively. However, this research is the first in the literature that discusses the issue from this point of view and shows that the pattern of bleeding basically follows the medial circumflex artery, without correlation with BMI, gender or type/degree of osteoarthritis. Osteoarthritis of the hip does not seem to modify the pattern of blood flow of the femoral head, and there is no evidence to support the fact that circulation in the femoral head decreases with aging. ${ }^{4}$

\section{CONCLUSIONS}

Macroscopic and subjective assessment of bleeding from the femoral head with osteoarthritis in 103 hips submitted to total primary arthroplasty showed that the anterior and superior quadrant had the lowest bleeding after bone perforation, while the posterior and inferior quadrants recorded a higher early bleeding.

\section{REFERENCES}

1. Zlotorowicz M, Szczodry M, Czubak J, Ciszek B. Anatomy of the medial femoral circumflex artery with respect to the vascularity of the femoral head. J Bone Joint Surg Br. 2011;93(11):1471-4.

2. Tucker FR. Arterial supply to the femoral head and its clinical importance. $J$ Bone Joint Surg Br. 1949;31(1):82-93.

3. Howe WW Jr, Lacey T, Schwartz RP. A study of the gross anatomy of the arteries supplying the proximal portion of the femur and the acetabulum. $J$ Bone Joint Surg Am. 1950;32(4):856-66.

4. Trueta J, Harrison MH. The normal vascular anatomy of the femoral head in adult man. J Bone Joint Surg Br. 1953;35(3):442-61.

5. Judet J, Judet R, Lagrange J, Dunoyer J. A study of the arterial vascularization of the femoral neck in the adult. J Bone Joint Surg Am. 1955;37(4):663-80.

6. Sevitt S, Thompson RG. The distribution and anastomoses of arteries supplying the head and neck of the femur. J Bone Joint Surg Br. 1965;47:560-73.

7. Crock $\mathrm{H}$. A revision of the anatomy of the arteries supplying the upper end of the human femur. J Anat. 1965:99:77-88.

8. Müssbichler $\mathrm{H}$. Arteriographic investigations of the normal hip in adults: evaluation of methods and vascular findings. Acta Radiol Diagn (Stockh). 1971;11(2):195-215.

9. Chung SM. The arterial supply of the developing proximal end of the human femur. J Bone Joint Surg Am. 1976;58(7):961-70.

10. Lavigne M, Kalhor M, Beck M, Ganz R, Leunig M. Distribution of vascular foramina around the femoral head and neck junction: relevance for conservative intracapsular procedures of the hip. Orthop Clin North Am. 2005;36(2):171-6.
11. Gautier E, Ganz K, Krügel N, Gill T, Ganz R. Anatomy of the medial femoral circumflex artery and its surgical implications. J Bone Joint Surg $\mathrm{Br}$. 2000;82(5):679-83.

12. Kalhor M, Beck M, Huff TW, Ganz R. Capsular and pericapsular contributions to acetabular and femoral head perfusion. J Bone Joint Surg Am. 2009:91(2):409-18.

13. Boraiah S, Dyke JP, Hettrich C, Parker RJ, Miller A, Helfet D, et al. Assessment of vascularity of the femoral head using gadolinium (Gd-DTPA)-enhanced magnetic resonance imaging: a cadaver study. J Bone Joint Surg Br. 2009;91(1):131-7.

14. Grose AW, Gardner MJ, Sussmann PS, Helfet DL, Lorich DG. The surgical anatomy of the blood supply to the femoral head: description of the anastomosis between the medial femoral circumflex and inferior gluteal arteries at the hip. J Bone Joint Surg Br. 2008;90(10):1298-303.

15. Jedral T, Anyzewski P, Ciszek B, Benke G. Vascularization of the hip joint in the human fetuses. Folia Morphol. (Warsz) 1996;55(4):293-4

16. Schoeniger R, Espinosa N, Sierra R, Leunig M, Ganz R. Role of the extraosseus blood supply in osteoarthritic femoral heads? Clin Orthop Relat Res. 2009;467(9):2235-40.

17. Ganz R, Gill TJ, Gautier E, Ganz K, Krügel N, Berlemann U. Surgical dislocation of the adult hip a technique with full access to the femoral head and acetabulum without the risk of avascular necrosis. J Bone Joint Surg Br. 2001;83(8):1119-24.

18. Bombelli R. Artrosis de la cadera. Clasificación y patogenia. Función de la osteotomía como terapéutica consiguiente. Barcelona: Salvat; 1985.

19. Kellgreen, JH, Lawrence JS. Radiological assessment of osteroarthrosis. Ann Rheum Dis. 1957;16(4):494-502. 